\title{
Evaluation of Sequential Extraction Schemes for the ETAAS Determination of Cadmium Concentrations in Coal Samples from the Thar Coalfield, Pakistan
}

\author{
Ayaz A Lashari ${ }^{\text {a }}$, Tasneem G Kazi ${ }^{\text {a }}$, Jamshed Ali*, a, b, Hassan I. Afridia ${ }^{\text {, Jameel A. Baig }}{ }^{\text {a }}$ \\ ${ }^{a}$ National Centre of Excellence in Analytical Chemistry, University of Sindh, Jamshoro 76080, Pakistan \\ ${ }^{b}$ Department of Petroleum and Chemical Technologies, \\ The Benazir Bhutto Shaheed University of Technology and Skill Development, Khairpur Mirs, Pakistan
}

\section{INTRODUCTION}

One of the major sources of energy production is coal $(1,2)$ which results in the release of many toxic elements into the atmosphere such as $\mathrm{Cd}, \mathrm{Pb}$, As, and $\mathrm{Hg}$ (3). Coal has its origin in the swampy and humid environments from buried plants and animals decaying over hundreds of millions of years which then form coal (4). Other basic elements in coal are carbon, hydrogen, nitrogen, oxygen, and sulfur (weight $>1 \%$ ). The release of these elements into the environment in the process of generating power causes serious health problems $(5,6)$. It is, therefore, important to evaluate the presence of toxicants in the coal regions (710).

The U.S. Environmental Protection Agency has reported that atmospheric pollutants released from coal include not only $\mathrm{SO}_{2}$, $\mathrm{NO}_{\mathrm{x}}$, and some organic compounds but also dust and heavy metals, causing cancer, especially from particulates, and from toxic $\mathrm{Cd}^{+2}$ at the sub-micron levels (11-15). The maximum permissible exposure limit (PEL) by Occupational Safety and Health Association (OSHA) for Cd in fumes is about $5.0 \mu \mathrm{g} / \mathrm{m}^{3}$ (16).

The metals and metalloids in sediment, soil, coal, and rocks are bound within the various chemical fractions in the form of oxyhydroxides of aluminum, iron/manganese, organic matter, sulfides, and carbonates $(17,18)$. Furthermore,

\footnotetext{
* Corresponding autbor.

E-mail:ajamshed75@yaboo.com

Tel: $+92-0222-771379$

Fax: +92- 0221 - 771560
}

\begin{abstract}
The present study evaluates the chemical fractionation of cadmium (Cd), a toxic heavy metal found in the coal samples of the Thar coalfield, Pakistan. An ultrasonic-assisted single-step extraction (USE) method was developed based on the reagents employed in the BCR three-step sequential extraction scheme (BCR-SES) for partitioning of $\mathrm{Cd}$ in coal samples. Validation of the methods was verified using certified reference material (CRM) BCR-701 Sediment and the standard addition method (recoveries $>97 \%$ ). The Cd extracted through the different fractions from the CRM and the coal samples was determined by electrothermal atomic absorption spectrometry (ETAAS). The main advantage of USE is that it enhances the extraction efficiency of $\mathrm{Cd}$ and reduces the time from 51 hours to 2 hours using the same experimental conditions as applied for BCR-SES. The concentrations of $\mathrm{Cd}$ in terms of its mobility in the real samples were observed in decreasing order: acid soluble fraction $<$ reducible fraction $<$ oxidizable fraction. The extracted Cd obtained with BCR-SES and USE was about $6.32 \%$ lower in the coal samples obtained from the area of block-X in comparison to block-XI.
\end{abstract}

these metal ions are not extracted from these solid segments by means of different procedures such as outer and inner sphere surface complexation, ion exchange (adsorption), and co-precipitation or precipitation (19).

The well-recognized sequentional extraction scheme (SES) pro- cedures are used to analyze the chemical fractions of the elements that are distributed in coal, rock, soil, and sediments by enhancing the reactivity of the metal (20-23). The main limitation of SES is the time required (about 51 hours) to analyze all chemical fractions of heavy toxic elements. However, the use of ultrasound energy has been reported to speed up the SES methods and break larger particles into smaller ones, producing a new surface for analysis of the sample solutions $(24,25)$.

The main goal of this work was to determine the various fractions of extractable Cd in coal samples using the Community Bureau of Reference sequential extraction scheme (BCR-SES) for the analysis of coal samples found in two areas (referred to as block-X and block-XI) of the Thar coalfield, Pakistan. For comparison, the modified ultrasonicassisted single-step extraction (USE) was also carried out using the same operating conditions as those applied in BCR-SES. The determination of accuracy for the proposed methods was validated with the certified reference material (CRM) BCR-701 Sediment (European Commission, Brussels, Belgium) and using the standard additions method with good percentage recoveries. The Cd concentrations of the coal samples were determined by electrothermal atomic absorption spectrometry (ETAAS) $(26,27)$.

\section{METHODOLOGY}

\section{Location of Sampling Area (Block-X and Block-XI)}

The Tharparkar district is situated in the desert of the southeast- 
ern part of Sindh province, Pakistan, on the boundary of the Western Indian platform (Singhvi and Kar 2004) (see Figure 1). Large coal deposits were found in 1992 in the Thar district by the Geological Survey of Pakistan (GSP) which was organized by the U.S. Geological Survey (USGS). The coal field has approximately 175 billion tons (BT) of coal and covers an area of 9100 $\mathrm{km}^{2}$ with $140 \mathrm{~km}$ north to south and $65 \mathrm{~km}$ east to west $(28,29)$.

\section{Collection of Samples}

Fresh composite coal samples $(n=20)$ were obtained and drilled from two areas identified as block-X and block-XI by permission of the Sindh coal authority. The samples were obtained by stratified probability sampling and placed into clean polypropylene bags to avoid contamination due to weathering conditions. They were dried in an electric oven at $105^{\circ} \mathrm{C}$ for one hour, ground through a 100-mesh sieve screen, and stored in plastic bags to protect them from environmental contamination.

\section{Reagents and Glassware}

Concentrated $\mathrm{HCl}, \mathrm{HNO}_{3}$, and $\mathrm{H}_{2} \mathrm{O}_{2}$ were purchased from Merck (Darmstadt, Germany). For calibration, a standard stock solution of Cd (1000 ppm) was used. The deionized water $(0.05 \mu \mathrm{S} / \mathrm{cm})$ of resistance was obtained using an
ELGA laboratory aqueous system (Bucks, UK). The chemicals used as the extractant were $\mathrm{CH}_{3} \mathrm{COO} \mathrm{NH}_{4}$ (Sigma-Aldrich, Milwaukee, WI, USA), $\mathrm{CH}_{3} \mathrm{COOH}$ and $\mathrm{NH}_{2} \mathrm{OH}-\mathrm{HCl}$ (Merck, Darmstadt, Germany) and applied to different fractional conditions. A Pd stock standard (3000 $\mathrm{mg} / \mathrm{L})$ was also prepared (99.999\%) (Sigma-Aldrich). $\mathrm{Mg}\left(\mathrm{NO}_{3}\right)_{2}$ was used to prepare the stock standard solutions $(2000 \mathrm{mg} / \mathrm{L})$ of the $\mathrm{Mg}\left(\mathrm{NO}_{3}\right)_{2}$ chemical modifiers (Merck). Reproducibility of the methods was checked using the CRM BCR 701 Sediment sample (Certified Reference Material, Europeon Commision, Brussels, Belgium).

\section{Instrumentation}

A model AAnalyst ${ }^{\mathrm{TM}} 700$ doublebeam atomic absorption spectrometer (PerkinElmer, Inc., Shelton, CT, USA), equipped with a deuterium lamp for background correction, $\mathrm{HGA}^{\circledR}-400$ graphite furnace, and AS-800 autosampler, was used for the determination of Cd. Composition of the modifier and the ETAAS experimental conditions are described in a previous study (30). A single-element hollow cathode lamp for Cd was operated at $7.5 \mathrm{~mA}$ with a spectral bandwidth of $1.3 \mathrm{~nm}$. The analytical wavelength of $\mathrm{Cd}$ was set at $228.8 \mathrm{~nm}$ as shown in (Table I). The graphite furnace heating program for Cd was set for different steps: drying, ashing, atomization, and cleaning as temperature range ${ }^{\circ} \mathrm{C} /$ time (s) 80-120/15, 300-600/15, 1500-1800/5 and 1800-2000/2, respectively. The sample solution and chemical modifier solution $(10+10 \mu \mathrm{L})$ were introduced directly into the graphite furnace. Argon gas was used as the carrier gas at a flow rate of $200 \mathrm{~mL} / \mathrm{min}$ for each analysis, and the deuterium lamp was used for background correction.

\section{Sample Procedure}

An end-over-end mechanical shaker (Gallankamp, Germany) was used for shaking. A ROWKA laboratory type WE-1, No. 6933, centrifuge (Mechanika Phecyzyjna, Poland) was used for phase separation. For $\mathrm{pH}$ adjustment and measuring, a model Ecoscan Ion $6 \mathrm{pH}$ meter (Malaysia, Kuala Lumpur) was used. A programmable model SC-121TH ultrasonic water bath (Sonicor Corporation, Deer Park, NY, USA) with an intensification of frequency at 35 $\mathrm{kHz}$ and a temperature range of 0 to $80^{\circ} \mathrm{C}$ was used for the fractions.

\section{EXPERIMENTAL DESIGN}

\section{Sequential Extraction Procedure}

Different extractants $\left(\mathrm{CH}_{3} \mathrm{COO}\right.$ $\mathrm{NH}_{4}, \mathrm{CH}_{3} \mathrm{COOH}$, and $\mathrm{NH}_{2} \mathrm{OH}-\mathrm{HCl}$ ) were used for the extraction of $\mathrm{Cd}$ (see Figure 2), and step-wise extrac-

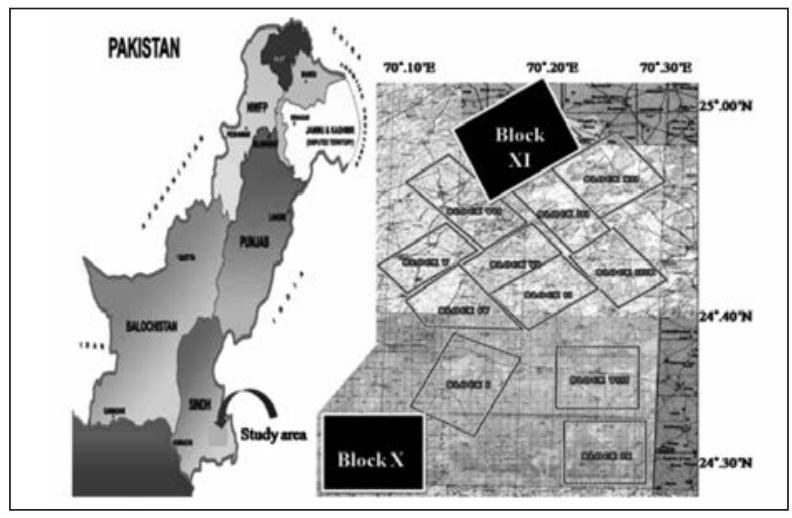

Fig. 1. Map showing study location of blocks ( $X$ and XI) of the Thar coalfield.
TABLE I

ETAAS Instrumental Operating Parameters

\begin{tabular}{ll}
\hline Parameters & Cadmium \\
\hline Lamp current & $7.5 \mathrm{~mA}$ \\
Wavelength & $228.8 \mathrm{~nm}$ \\
Slit width & $1.3 \mathrm{~nm}$ \\
Cuvette & Cup \\
\hline Common Parameters & \\
\hline Sample volume & $10 \mu \mathrm{L}$ analyte $+10 \mu \mathrm{L}$ \\
& corresponding modifiers \\
Background correction & $\mathrm{D}_{2}$ lamp \\
Carrier gas argon & $200 \mathrm{~mL} / \mathrm{min}$ \\
\hline
\end{tabular}


tions were carried out by the procedure as given below. The coal samples (air-dried) in triplicate from block-X and block-XI and six samples of CRM BCR-701 Sediments were placed into an oven at $100 \pm 5$ ${ }^{\circ} \mathrm{C}$ to dry for 2-3 hours until constant weight was obtained $(31,32)$. For each set of analyses, blank extractions (with no sample) were also performed during the whole procedure. For BCR-SES, the stepwise extractions were carried out in a mechanical end-over-end shaker at the speed of $3000 \mathrm{rpm}$ and shaken up to $30^{\circ} \mathrm{C}(33,34)$. The time-saving USE method was performed in an ultrasonic bath with the cooling effect provided in the bath at $35 \mathrm{kHz}$ frequency, $30-35^{\circ} \mathrm{C}$, up to 30 minutes ultrasound exposure.

\section{Three-stage Sequential Extraction of Cd}

Fraction 1: A 20-mL amount of acetic acid $(0.11 \mathrm{M})$ was added to $0.5 \mathrm{~g}$ of the air-dried CRM BCR-701 Sediment and the coal samples, and shaking was carried out for 16 hours. For separation of the extract from the residue, the mixture was centrifuged.

Fraction 2: A 20-mL amount of hydroxyl ammonium chloride was newly prepared, the $\mathrm{pH}$ adjusted to 1.5 with $\mathrm{HNO}_{3}$ (as shown in Figure 2 ), then the residue from fraction 1 was added, and the extraction carried out as performed in fraction 1 .

Fraction 3: The residue resulting from fraction 2 was treated twice with $5 \mathrm{~mL}$ of $\mathrm{H}_{2} \mathrm{O}_{2}(30 \%)$, evaporated to dryness, and then $25 \mathrm{~mL}$ of $\mathrm{CH}_{3} \mathrm{COO} \mathrm{NH}_{4}(\mathrm{pH}$ kept at 2 by using nitric acid) was added, and the extraction carried out as performed in fraction 2 .

The simultaneous washing of the residue with ultrapure water, shaking for 15 minutes, and centrifugation at $3000 \mathrm{rpm}$ for 20 minutes was carried out between each extraction step. Discarding of any residue was avoided by carefully decanting the supernatant. This procedure was applied in order to remove any other interfering elements and the other reacting species in coal residues from the previous fraction.

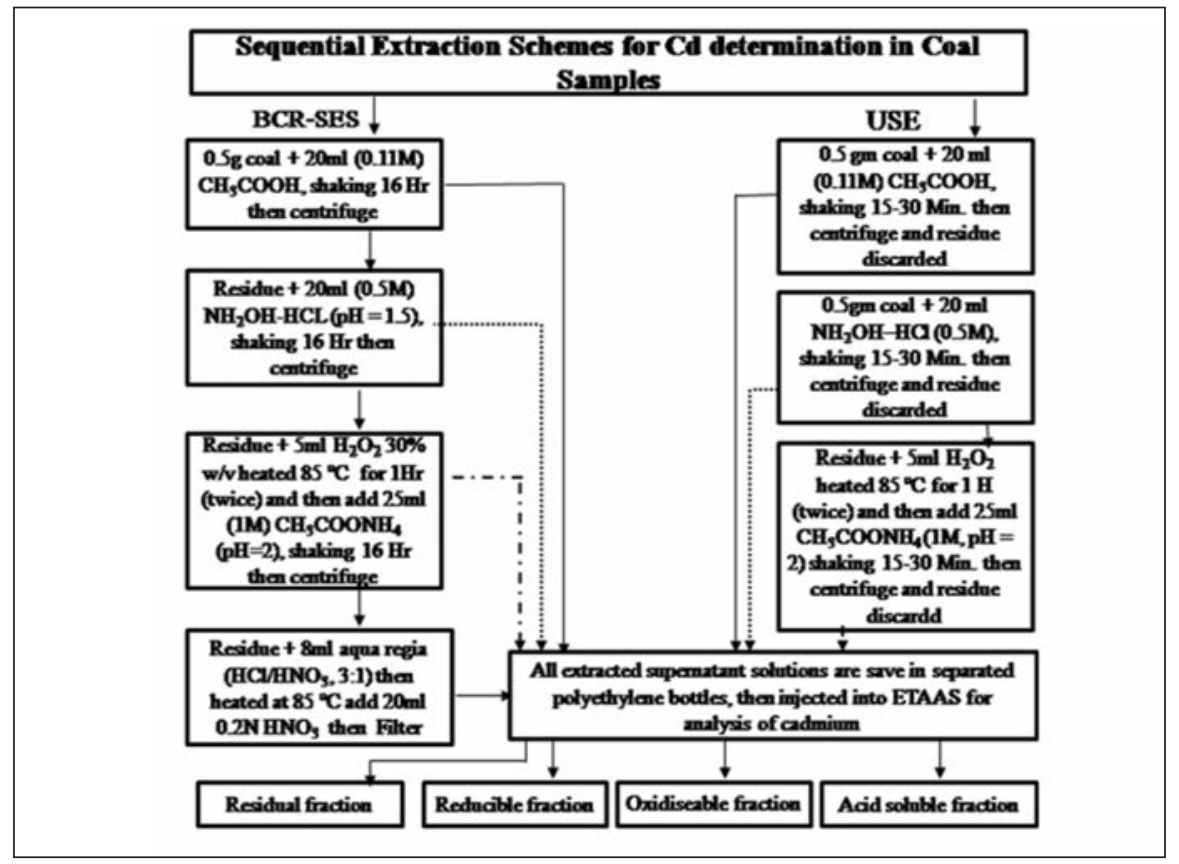

Fig. 2. Flow chart of BCR-SES and ultrasonic-assisted single-step extraction.

\section{Atomic Apectroscopy \\ Vol. 39(5), Sept./Oct. 2018}

Residual fraction: The remaining substance at the end of the BCR-SES procedure was carried through microwave digestion and using aqua regia.

\section{Digestion Process for Residue and Total Concentration of $\mathbf{C d}$}

Microwave-assisted digestion was applied for the determination of pseudo-total Cd concentrations in the coal samples with aqua regia. The residue obtained from the fraction and $0.5 \mathrm{~g}$ of coal samples (airdried) were placed into 25-mL PTFE flasks. Then $6 \mathrm{~mL}$ of concentrated $\mathrm{HCl}(37 \%)$ and $2 \mathrm{~mL}$ of concentrated $\mathrm{HNO}_{3}(65 \%)$ were added, and kept standing for 10 minutes at room temperature. Then, the covered PTFE flasks were heated in a domestic microwave oven up to $80 \%$ at $900 \mathrm{~W}$ total maximum power (35). Excess acid was removed by cooling and evaporating the resulting solution. Then 10 $\mathrm{mL}$ of nitric acid $(0.2 \mathrm{M}, \mathrm{mL})$ was added to the digested samples and filtered through a Whatman No. 42 filter paper. This was further diluted with ultrapure water and brought to $25-\mathrm{mL}$ volume. The $\mathrm{Cd}$ concentration in the coal samples was determined by ETAAS (36).

\section{Ultrasonic-assisted Single-step Extraction}

For the sonication method, an ultrasonic bath was used which allows analyzing several samples at the same time. Thus, all of these conditions were designed to give maximum extraction in the shortest possible time temperature of the samples since this can change the chemical equilibrium of the extraction solutions. When all of the conditions of sonication were optimized, the BCR sequential extraction method was applied to CRM BCR701 Sediment and the real coal samples. The most favorable experimental conditions for each fraction were obtained using an ultrasonic bath for 15 to 30 minutes at $35 \mathrm{kHz}$ 
frequency, and a temperature of 30 to $35^{\circ} \mathrm{C}$ (37). The different fractions were handled as described in the sequential extraction procedure section and are illustrated in Figure 2 .

\section{Analytical Performance}

For the calibration graph, the linear range was obtained with 1 to $25 \mu \mathrm{g} / \mathrm{L} \mathrm{Cd}$ standards. The equation for the calibration graph was $\mathrm{Y}=(0.009)(\mathrm{Cd})+(0.661)$, where $\mathrm{Y}$ is the peak area of integrated absorbance and measurement. The limit of detection (LOD) and limit of quantification (LOQ) for Cd were calculated as follows: $\mathrm{LOD}=3 \times \mathrm{SD} / \mathrm{m}$, resulting in $0.6 \mu \mathrm{g} / \mathrm{kg} \mathrm{Cd}$, and $\mathrm{LOQ}=10 \times \mathrm{SD} / \mathrm{m}$, resulting in 2.2 $\mu \mathrm{g} / \mathrm{kg} \mathrm{Cd}$, where $\mathrm{m}$ represents the calibration slope and SD shows the standard deviation corresponding to 10 blank measurements.

\section{RESULTS AND DISCUSSION}

\section{Validation and Comparison of Proposed Methods}

Analysis of the CRM BCR-701 Sediment and use of the standard addition method were carried out to establish accuracy and precision of the proposed methods for the chemical fractionation of cadmium. The validity of the method for BCR-
701 along with the standard addition method was carried out by spiking the Cd standards in a controlled environment at three concentrations (38). The BCR-SES and the time-saving single-step USE method were used for the coal samples from two respective blocks ( $\mathrm{X}$ and XI) at the Thar coalfield, Pakistan. The three fractions of BCRSES (fraction 1, fraction 2, and fraction 3) were confirmed through percentage recoveries and found to be $>98.0 \%$ (Table II). The (\%) recovery was calculated by using the formula

$$
\begin{aligned}
& \text { \%Recovery }= \\
& \text { Cd exracted through proposed BCR-SES }
\end{aligned}
$$

The comparative study between pseudo-total results and those obtained by BCR-SES ( $\Sigma$ three steps + residual) using digestion of the coal samples with aqua regia showed that the difference was not significant (Table II). The relative errors and (\%) recovery $(<1.0 \%$ and $>98$ ) of the proposed BCR-SES and USE methods were valid (Table II). Since no coal CRM is available, accuracy of the two extraction methods was evaluated by means of three duplicate sub-samples of the studied coal samples and spiking them with three known concentrations of Cd standards. To obtain the (\%) recovery, the following formula was used for calculation:

$\%$ Recovery $=\frac{\mathrm{C} \text { spiked }-\mathrm{C} \text { unspiked }}{\mathrm{C}_{\mathrm{s}}}$

where:

$\mathrm{C}$ spiked $=\mathrm{Cd}$ concentration after addition of Cd standard solution to coal sample;

$\mathrm{C}$ unspiked $=\mathrm{Cd}$ concentration before addition of Cd standard solution to coal sample;

$\mathrm{C}_{\mathrm{s}}=$ added concentration of standard solution of $\mathrm{Cd}$

The Cd percentage recoveries in all fractions of BCR-SES and USE were $>97 \%$, showing little difference ( $p>0.05)$ for the applied methods (Table III) .The comparison between the BCR-SES and USE methods was calculated by using the paired t-test and also compared the t-experimental (tExp) value to that of the theoretical value (tCritical) at the confidence limit $>94 \%$ (Table II). In the case of the three fractions of $\mathrm{Cd}$, the tExp was found at $0.002,0.041$, and 0.31 , which is less than the tCritical value (3.12). The proposed USE extraction method was performed using single-step extraction of all fractions and requires less time ( 2 hours) in comparison to the BCR-SES method

\begin{tabular}{|c|c|c|c|c|c|c|}
\hline BCR- 701 & Acid Soluble Cd & Reducible Cd & Oxidizable Cd & Residual Cd & $\begin{array}{c}\text { Three }[\Sigma] \\
\text { steps+residual }^{c}\end{array}$ & Pseudo-total Cd \\
\hline Certified Values & $7.34 \pm 0.35$ & $3.77 \pm 0.28$ & $0.27 \pm 0.006$ & - & - & - \\
\hline BCR-SES ${ }^{\mathrm{a}}$ & $7.23 \pm 0.57$ & $3.73 \pm 0.28$ & $0.27 \pm 0.08$ & $0.23 \pm 0.04$ & $11.4 \pm 0.87$ & $\begin{array}{c}11.5 \pm 0.89 \\
(7.73)\end{array}$ \\
\hline $\mathrm{USE}^{\mathrm{b}}$ & $7.12 \pm 0.23$ & $3.76 \pm 0.21$ & $0.28 \pm 0.02$ & - & - & $\begin{array}{c}- \\
(7.14)\end{array}$ \\
\hline \%Recovery & 98.5 & 101 & 104 & - & - & - \\
\hline $\begin{array}{l}\mathrm{t}_{\text {values }} \text { at } \mathrm{df}=5, \\
\mathrm{t}_{\text {Critical }}=3.12\end{array}$ & 0.002 & 0.041 & 0.31 & - & - & - \\
\hline
\end{tabular}

TABLE II

Chemical Fractionation of Cd (mg/kg) for CRM BCR-701 Sediment Using BCR-SES and USE

\footnotetext{
${ }^{a}$ Sequential extraction scheme.

${ }^{b}$ Ultrasonic-assisted single extraction.

${ }^{\mathrm{c}}$ Relative standard deviation.
} 
which is more time-consuming (51 hours) (39). The USE extraction method requires a larger sample volume, but this is not a drawback because environmental samples are generally abundant. The results were not significantly different in the acid soluble fractions extracted from BCR-SES and USE schemes. The extracted Cd concentrations by USE extraction were considerably greater in the reducible fraction $(>9.2 \%)$ in comparison to BCR-SES (>2.2\%) for the oxidizable fraction (Table III). The values of percentage relative standard deviation (\% RSD) by the proposed methods were $>10 \%$ which further confirms the reproducibility of the proposed methods (Table II).

\section{Total Cadmium in Coal}

The pseudo-total concentrations of Cd were determined by digesting each coal sample in aqua regia. The Cd values obtained from each fractionation step, using both extraction schemes (BCR-SES and USE), show similar results. The BCR-SES and USE methods were also applied for the determination of pseudototal and the sum of fractions $(\Sigma$ fraction $1+$ fraction $2+$ fraction 3 ) extracted from the coal samples and using similar operating conditions. The pseudo-total and sum of extractable fractions in block $\mathrm{X}$ contained $4.29 \mathrm{mg} / \mathrm{kg} \mathrm{Cd}$ and 4.21 $\mathrm{mg} / \mathrm{kg} \mathrm{Cd}$, respectively, but for block XI the Cd concentration was $4.73 \mathrm{mg} / \mathrm{kg}$ and $4.855 \mathrm{mg} / \mathrm{kg}$, respectively (Table IV).

\section{Acid-soluble Fraction}

The acid-soluble extractable fraction contains a minute percentage of toxic heavy metals (2.1\%) because it precipitated or co-precipitated with carbonate which likely changes with environmental conditions. This phase is liable to change with $\mathrm{pH}$, so a mild acid was used to dissolve $\mathrm{CO}_{3}{ }^{2-}$ without dissolving the alumino-silicates, $\mathrm{Fe} / \mathrm{Mn}$ oxides, and organic matter (40). In the acid-soluble fraction, the toxic Cd concentration was found at $3.2 \%$ to $2.6 \%$ in the coal samples from block X and block XI, respectively, with a percentage recovery of $>3.7 \%$ in block X (Table IV).

\section{Reducible Fraction}

The reducible fraction represents the metals bound to iron and man-

TABLE III

Results for Standard Addition/Recovery Test for Cd Concentration in Composite Coal Samples From Blocks X and XI ( $\mathrm{mg} / \mathrm{kg})$

\begin{tabular}{|c|c|c|c|c|c|c|c|c|c|c|c|c|c|}
\hline \multirow[t]{2}{*}{ Blocks } & \multirow{2}{*}{$\frac{\text { Add }}{(\mathrm{mg} \mathrm{L})}$} & \multicolumn{4}{|c|}{ Acid Soluble Cd } & \multicolumn{4}{|c|}{ Reducible Cd } & \multicolumn{4}{|c|}{ Oxidizable Cd } \\
\hline & & $\begin{array}{l}\text { BCR- } \\
\text { SES }\end{array}$ & $\%$ Rec & USE & $\% \mathrm{R}$ & $\begin{array}{l}\text { BCR- } \\
\text { SES }\end{array}$ & $\% \mathrm{R}$ & USE & $\% R$ & $\begin{array}{l}\text { BCR- } \\
\text { SES }\end{array}$ & $\% \mathrm{R}$ & USE & \%Rec. \\
\hline \multirow[t]{4}{*}{$\mathrm{X}$} & 0 & 0.142 & - & 0.152 & - & 1.01 & - & 1.12 & - & 2.51 & - & 2.68 & - \\
\hline & 5 & 5.08 & 98.7 & 5.19 & 100 & 5.91 & 98.0 & 6.10 & 99.6 & 7.41 & 98.0 & 7.71 & 100 \\
\hline & 10 & 10.1 & 99.5 & 10.0 & 98.4 & 11.1 & 100 & 11.2 & 100 & 12.3 & 98.0 & 12.8 & 101 \\
\hline & 15 & 15.0 & 99.0 & 14.8 & 98.0 & 15.9 & 99.2 & 16.1 & 99.8 & 17.4 & 99.2 & 17.6 & 99.4 \\
\hline \multirow[t]{4}{*}{$\mathrm{XI}$} & 0 & 0.134 & - & 0.139 & - & 1.18 & - & 1.34 & - & 2.87 & - & 2.91 & - \\
\hline & 5 & 5.10 & 99.3 & 5.11 & 99 & 6.17 & 99.8 & 6.31 & 99.4 & 7.79 & 98.4 & 7.89 & 99.6 \\
\hline & 10 & 10.2 & 100 & 10.1 & 99.6 & 11.1 & 99.4 & 11.4 & 100 & 12.8 & 99.3 & 12.9 & 99.9 \\
\hline & 15 & 15.1 & 99.7 & 15.0 & 99 & 16.0 & 99.0 & 16.5 & 101 & 17.7 & 98.8 & 18.2 & 101 \\
\hline
\end{tabular}

TABLE IV

Chemical Partitioning of Cd in Coal Samples in Block X and XI by BCR-SES and USE

\begin{tabular}{|c|c|c|c|c|c|c|c|c|}
\hline Blocks & $\begin{array}{l}\text { Extraction } \\
\text { Scheme }\end{array}$ & $\begin{array}{l}\text { Acid-Soluble } \\
\text { Cd }\end{array}$ & $\begin{array}{c}\text { Reducible } \\
\text { Cd }\end{array}$ & $\begin{array}{c}\text { Oxidizable } \\
\text { Cd }\end{array}$ & $\begin{array}{c}\text { Residual } \\
\text { Cd }\end{array}$ & $\begin{array}{l}\text { Three steps }[\Sigma] \\
\text { +Residual } \\
\text { Fractions }\end{array}$ & $\begin{array}{l}\text { Pseudo-total } \\
\text { Cd }\end{array}$ & $\mathrm{C}_{\mathrm{f}}$ \\
\hline \multirow[t]{3}{*}{$\mathrm{X}$} & BCR-SES & $0.138 \pm 0.014$ & $0.958 \pm 0.089$ & $1.64 \pm 0.041$ & $1.48 \pm 0.028$ & $4.21 \pm 0.528$ & $4.29 \pm 0.568$ & 1.85 \\
\hline & USE & $0.141 \pm 0.021$ & $0.941 \pm 0.091$ & $1.60 \pm 0.022$ & NDa & ND & & \\
\hline & (\%)Recovery & 102.1 & 98.2 & 97.5 & ND & ND & & \\
\hline \multirow[t]{3}{*}{ XI } & BCR-SES & $0.128 \pm 0.028$ & $0.878 \pm 0.014$ & $1.75 \pm 0.071$ & $2.10 \pm 0.081$ & $4.86 \pm 1.05$ & $4.73 \pm 0.721$ & 1.31 \\
\hline & USE & $0.126 \pm 0.026$ & $0.865 \pm 0.051$ & $1.71 \pm 0.069$ & ND & ND & & \\
\hline & (\%)Recovery & 98.4 & 98.5 & 97. & ND & ND & & \\
\hline
\end{tabular}


ganese oxides that are released when the matrix is subjected to reducing conditions (41). Coal is found to be less abundant when these oxides are present, while soil and other solid samples are found to be more abundant. The chemical extractant most commonly used to leach the reducible fraction easily from the sample is hydroxylamine hydrochloride $(0.5 \mathrm{M})$ and adjusting the $\mathrm{pH}$ to 1.5 with $\mathrm{HNO}_{3}$. The cadmium present in this fraction using BCR-SES was $22.7 \%$ and $18 \%$ for block X and block XI, respectively. With USE, no significant difference was observed $(\mathrm{p}<0.05)$ and good recoveries (> 98\%) were obtained (see in Table IV).

\section{Oxidizable Fraction}

The oxidizing fraction involves organic matter and sulfides present with the toxic metals which can be easily released under oxidizing conditions. In this work, the oxidant used was $\mathrm{H}_{2} \mathrm{O}_{2}$ in acid media (42). Commonly, $\mathrm{H}_{2} \mathrm{O}_{2}$ is used to dissolve organic matter at a temperature up to $85^{\circ} \mathrm{C}$ for two hours which also lowers the possibility of silicate change. However, care must be practiced when heating hydrogen peroxide up to $85^{\circ} \mathrm{C}$. The $\mathrm{Cd}$ metal found in the oxidizable fraction was from $36 \%$ to $39 \%$ of total $\mathrm{Cd}$ in the coal samples from block $\mathrm{X}$ and block XI, respectively. The percent recoveries were $(p<0.05)$ in comparison to the other fractions (Table IV).

\section{Residual Fraction}

The non-extractable or residual fraction of the metal is retained inside crystallized oxides and within the lattices of crystal minerals. Toxic Cd was found to be present at higher concentrations in block X than in block XI (43.2\% of total Cd extracted).

\section{Contamination Factor of Cd}

The contamination factor $\left(C_{f}\right)$ for Cd was also calculated by using the following formula:

$$
\mathrm{C}_{\mathrm{f}}=\frac{\text { EFraction 1 + Fraction 2 + Fraction 3 }}{\text { Residual Fraction }}
$$

The high $\mathrm{C}_{\mathrm{f}}$ values indicate the presence of higher Cd concentrations in the coal resulting in contamination risk for biota, groundwater, and the environment. The $\mathrm{C}_{\mathrm{f}}$ for block $\mathrm{X}$ and block XI was found to be 1.85 and 1.31 , respectively (Table III).

\section{CONCLUSION}

In this study, the toxic heavy metal cadmium (Cd) concentrations in solid coal samples were analyzed using the BCR-based ultrasonic-assisted single-step extraction (USE) method and for comparison by the BCR sequential extraction scheme (BCR-SES). The USE method enabled a reduction in extraction time, yielding extractable concentrations in accordance with those obtained by the application of BCRSES, which can be regarded as a standard method and was validated by using certified reference material BCR 701 Sediment. The main advantage of USE is that the long treatment time required in BCR-SES ( 51 hours) could be shortened to 2 hours by replacing the sequential treatment by single extractions. It was found that the total Cd concentration in the coal samples of the block $X$ area was $4.29 \pm 0.568$, which is $4.4 \%$ lower than from the block XI area at $4.73 \pm 0.721$ $(p<0.05)$. A major amount of cadmium (up to $43.2 \%$, that of total cadmium) was obtained in the residual fraction.

Received November 9, 2017.

\section{REFERENCES}

1. G. Liu, P. Yang, W. Zhang, G. Wang and Q. Feng, J. China. Univ. Min. Tech. (2000).
2. L. Thomas, A review of Handbook of coal geology, John Wiley and Sons Ltd., England, Pg. 4 (1992).

3. P. Marcal, F. Haidi and C.T. Elba, Fuel 76, 14 (1997) .

4.E. O. Adaikpoh, G. E. Nwajei and J.E. Ogala, J. Appl. Sci. and Environm. Management 9, 5 (2005).

5. R.B. Finkelman, D.J. Swaine and F. Goodarzi, Environmental Aspects of Trace Elements of Coal 1, 24 (1995).

6. S. Dai, D. Li, D. Ren, Y. Tang L. Shao and H. Song, Appl. Geochem. 19,1315 (2004).

7. Dai D. Ren, C.L.Chou, R.B.Finkelman, V.V. Seredin, and Y. Zhou, Intern. J. Coal Geol. 94, 3 (2012).

8. A. Ahmed, M.N. Chaudry, A.Shabbir and M. Ali, Pakistan J. Hydrocarb. Res. 22, 41 (2012).

9. R.B. Finkelman, Int. J. Coal Geol. 59, 19 (2004).

10. A. Ure and C. Davidson, Chemical speciation in the environment (2008).

11. D. Akers, and R. Dospoy, Reprints Society for Mining, Metallurgy, and Exploration Annual Meeting, Phoenix, AZ, USA,No. 92, 1 (1992).

12. D. Akers and R. Dospoy, Use of coal cleaning to reduce air toxics, Reprints Society for Mining, Metallurgy, and Exploration Annual Meeting, Phoenix, AZ, USA,. No. 92-1 (1992).

13. P.T. Williams, Pollutants from Incineration, In Waste incineration and the environment, pp. 27-52 (1994).

14. J. Jung and T. J. Logan, J Environm. Quality 21, 73 (1992).

15. M. Khan, T.G. Kazi, H.I.Afridi, Bilal, A.Akhtar, N. Ullah, S. Khan and S. Talpur, Ultrason.Sonochem. 39, 313 (2017).

16. O. Popović, R. Prokić-Cvetković, M. Burzić, U. Lukić, and B. Beljić, Ren. Sustain. Energy Rev. 37, 509 (2014).

17. C. Gleyzes, S.Tellier and M. Astruc, Trac. Trend Anal. Chem. 21, 45 (2002).

18. J. Ali, T.G. Kazi, J.A. Baig, H.I. 
Afridi, M.S. Arain, K.D. Brahman, N. Ullah, and A.H. Panhwar, Environ. Sci. Pollut. Res. 22, 8559 (2015).

19. A.J. Chandler, T.T. Eighmy, J. Hartlen, O. Hjelmar, D.S. Kosson, S.E. Sawell, H.A. Vander Sloot, and J. Vehlow, Studies In Environmental Science, Municipal solid waste incinerator residues. Vol. 67. Elsevier Publ. (1997).

20. C.M. Davidson and G. Delevoye, J. Environ. Monit. 3, 398 (2001).

21. A.V. Filgueiras, I. Lavilla and C. Bendicho, J. Environ. Monit. 4, 823 (2002).

22. G.M. Nystrøm, L.M. Ottosen and A .Villumsen J. de Phy IV (Proceedings) EDP Science, 975 (2003).

23. M. Zemberyova, J. Bartekova and I. Hagarova, Talanta 70, 973 (2006).

24. I. Ipolyi, C. Brunori, C. Cremisini, P. Fodor, L. Macaluso and R. Morabito, J. Environ. Monit. 4, 541 (2002).

25. M. Jamali, T. Kazi, M. Arain, H. Afridi, J. Baig and A. Shah, Act. Agrono Hung .57, 215 (2009).

26. N. Manutsewee, W. Aeungmaitrepirom, P. Varanusupakul and $\mathrm{A}$. Imyim, Food Chem. 101, 817 (2007).

27. M. Ghaedi, A. Shokrollahi, K. Niknam, E. Niknam, A. Najibi and M. Soylak, J. Hazard. Mater. 168, 1022 (2009)

28. A.H. Kazmi and P. MQJan, Geology and tectonics of Pakistan, Graphic Publishers. (1997)

29. M.S. Malkani, J. Sci. Technol. Dev. .31, 202 ( 2012).

30. M.K. Jamali, T.G. Kazi, H.I. Afridi, M.B. Arain and A.R. Memon, J. Environmental Science and Health, Part A, 42, 649 (2007).

31. T. Kazi, M. Jamali, M. Arain, H Afridi and A. Siddiqui, Anal. Bioanal. Chem. 383, 297 (2005).

32. P. Quevauviller, Trac Trends Anal Chem. 21, 774 (2002).

33. A.M. Ure, Ph. Quevauviller, H. Muntau and B. Griepink, Int. J. Environ. Anal. Chem, 51, 135 (1993).

34. J. Ali, T.G. Kazi, J.A. Baig, H.I.
Afridi, M.S. Arain, N. Ullah and S. Farooq, International J. Coal Geology 156, 50 (2016).

35. S. Demirel, M. Tuzen, S. Saracoglu and M. Soylak, J. Hazardous Materials 152, 1020 (2008).

36. A. Sahuquillo, G. Rauret, A. Rehnert and $\mathrm{H}$. Muntau, Anal. Chim. Acta 476, 15 (2003).

37. M.B. Arain, T.G. Kazi, M.K. Jamali, N. Jalbani, H.I. Afridi and J.A. Baig, J. Hazard. Materials 154, 998 (2008).

38. K.F. Mossop and C.M. Davidson, Ana. Chim. Acta 478, 111 (2003).

39. G.M. Greenway and Q.J. Song, J. Environ. Monit. 4, 950 (2002).

40. E.K.A. Hudson, M.G. Macklin, C.D Curtis and D. Vaughan, Environ. Sci. Technol, 30, 72 (1996).

41. A.F. Alborés, B.P. Cid, E.F. Gómez and E.F. López, Analyst. 125, 1353 (2000).

42. C.M. Davidson, L.E. Wilson and A.M. Ure, Fresen. J. Anal. Chem. 363, 134 (1999). 